\title{
Assessment of the Value of Health Provider Expectations: An Attempt to Fully Conceptualize Patient Satisfaction
}

\author{
Bennie Berkeley \\ University of Trinidad and Tobago, Wallerfield, Trinidad and Tobago \\ Email: bennieberkeley8@gmail.com
}

How to cite this paper: Berkeley, B. (2018) Assessment of the Value of Health Provider Expectations: An Attempt to Fully Conceptualize Patient Satisfaction. Open Access Library Journal, 5: e4679. https://doi.org/10.4236/oalib.1104679

Received: May 24, 2018

Accepted: June 23, 2018

Published: June 26, 2018

Copyright $\odot 2018$ by author and Open Access Library Inc.

This work is licensed under the Creative Commons Attribution International License (CC BY 4.0).

http://creativecommons.org/licenses/by/4.0/

\section{Open Access}

\begin{abstract}
This paper reports the results of an investigation to assess the value (validity and reliability) of health provider expectations in an attempt to broaden the construct "patient satisfaction". Data were collected from 25 health providers through a 16-item Likert-type survey. The variable "expectation" was measured by factors such as cleanliness, privacy, healthcare, space on hospital wards and adequacy of food servings. The data were analyzed and assessed using exploratory and confirmatory factor analyses. The results indicate that 11 of 16 factors loaded separately onto three components. However, only component two: (tidiness and cleanliness) comprising items 10, 15 and 16, proved to be significant (Average Variance Extracted $=0.512$, Construct Reliability $=0.740$; Cronbach's Alpha $=0.687)$. Furthermore, it was confirmed that item 15 was the strongest contributor to component two (Beta $=1.020)$. To test sampling adequacy and adequacy of correlation for factor loadings, Kaiser-Mayer-Olkin and Bartlett's Test of Sphericity respectively were performed. Despite sampling inadequacy $(0.440<0.60)$, the analysis proceeded owing to the fact that the result of Bartlett's test was statistically significant ( $\mathrm{p}$ $=0.006$ ). This paper concludes that the instrument should be modified and retested using larger samples of healthcare providers before a broad epistemological framework of patient satisfaction can be hypothesized.
\end{abstract}

\section{Subject Areas}

Public Health

\section{Keywords}

Health Provider Expectations, Patient Satisfaction, Epistemological Challenges 


\section{Introduction}

Many theories of patient satisfaction are limited to patient expectations and are concerned with the relationship between patient satisfaction and independent variables such as communication with health providers, attitude and care received. In other words, they are concerned with direct measurement of patient satisfaction. One example of direct measurement of patient satisfaction is found in Aragon and Gesell's [1] primary provider theory which purports that satisfaction with primary provider (doctor or physician) and waiting time have the most significant influence on patient satisfaction. This paper aims to assess health provider expectations of patient satisfaction. It represents the first step toward theoretical expansion of the construct of patient satisfaction by searching for indirect measures; that is, factors of health providers' expectation will have an influence on patient satisfaction. The objectives of this paper are to: 1) identify the number of components in a 16-item measure of patient satisfaction; 2) identify items related to each component; and 3) assess the contribution of each item to its component. Data were collected via a survey of healthcare workers attending a one day post graduate research seminar on health research at the University of Trinidad and Tobago (UTT) on June 24, 2017. All participants had graduated from or were pursuing the Master's in Health Administration (MHA) at the UTT.

This paper will provide a brief review of the main epistemological challenges in patient satisfaction studies. However, its departure from traditional patient satisfaction theory stands out because it incorporates the health provider's perspective. Additionally, its method is outlined. This is followed by a presentation, explanation and brief discussion of its findings. Finally, it ends by summarizing the main points and calls attention to the need for further research on health provider's expectations in patient satisfaction.

\section{Literature Review: Problems in Measuring Patient Satisfaction}

This review will be limited to five journal articles on the theory of patient satisfaction. It aims to demonstrate the main conceptual challenges in measuring patient satisfaction and to emphasize the centrality of patients in the measurement of satisfaction.

Thompson and Sunol [2] affirmed that there is a lack of conceptual agreement about the approach to understanding patient expectations of health providers. They attempted to distil the main definitions in use, illustrate practical models of the relationship between expectations and satisfaction, identify the influential personal and social variables, and consider the special nature of healthcare. Thompson and Sunol [2] reviewed 18 journals and a number of relevant books in order to understand the nature of patient satisfaction studies in the 1990s.

In another study Linder-Pelz [3] criticized the lack of conceptual clarity in the definition of patient or client satisfaction. Using Fishbein and Ajzeen's (cited in Linder-Pelz [3]) attitude theory from job satisfaction, she theorized that va- 
riables such as patient attitudes and perceptions prior to receiving healthcare were likely components or measures of patient satisfaction. Data for her study were obtained from reviews of social science theories.

Bathaatar et al. [4] argued that patient satisfaction is inherently bound up with quality healthcare. Through reviews of literature, they claimed that most of the patient satisfaction theories and formulations were based on marketing theories and on how well health service fulfilled patients' expectations. In addition, they argued that a relationship between expectation and satisfaction was unclear and that the concept of expectation was not distinctly theorized. (Bathaatar et al. p. 243) [4] In this current paper expectation implies health providers perception of things they assume will make patients happy or satisfied.

Hudak et al. [5] sought to develop a theory of patient satisfaction by relating treatment outcome to embodiment. They defined embodiment as body-self unity. Also they sought to examine their new theory in relation to other competing theories. Their main finding was that treatment outcome was significantly associated with embodiment. Three other findings: 1) cofounders-the extent to which surgery successfully addressed patients' most important reason for surgery 2) hindsight expectations and, 3) workers' compensation: were also significant. The final model explained $84 \%$ of the variance in patient satisfaction $(\mathrm{Hu}-$ dak et al. p. 526) [5]. Given the high variance observed, this model should be tested repeatedly to determine whether it is consistent over time.

In another study O'Connell, Young and Twigg [6] supported the claim that patient satisfaction is a major indicator of quality nursing care. They contended that the use of different measurements/theories creates problems of the validity of measurements of patient satisfaction. In order to address the problem of measurement, they discussed the findings of a patient satisfaction survey conducted in two acute care surgical wards using the revised 28-item La Monica-Oberst patient satisfaction scale and telephone interviews. Data were analyzed using descriptive statistics and textual methods. The latter were managed using NUD*IST and analyzed for common emerging themes and categories. O’Connell, Young and Twigg [6].

O'Connell, Young and Twigg [6] compared the findings of the quantitative and qualitative data in order to determine similarities and differences between them. Survey results revealed very high levels of patient satisfaction; however, the qualitative data pointed to anomalies in the survey such as participant difficulty in answering the questionnaire and inability to discriminate nursing care from the rest of their overall experience.

The main epistemological challenge was the lack of clarity in defining and measuring patient expectation and satisfaction. This was evidenced by the fact that researchers conceptualized patient satisfaction based on expectations about healthcare providers' attitudes, patient perceptions and treatment outcomes. In this paper, patient satisfaction was also conceptualized in terms of health provider expectations of factors perceived to make patients happy or satisfied. 


\section{Method}

Based on Krajcie and Morgan's [7] sample size rule for small populations $(\mathrm{N}<$ $100)$, the survey was administered to all participants $(\mathrm{N}=50)$ attending a one day research seminar on health related issues such as over-radiation, hypertension in pregnancy and patient satisfaction. Demographic data revealed that 25 of the 50 participants were healthcare providers. The rest were clerical (15) and secretarial workers (10) who scheduled appointments and performed routine office tasks in healthcare facilities such as state hospitals and district health facilities. To address objective one, Exploratory Factor Analysis (EFA), involving Principal Component Analysis (PCA) and Varimax Rotation (VR), was performed in order to identify the number of components. Eigenvalues greater than 1 were considered to be acceptable. To address objective two, Confirmatory Factor Analysis (CFA) was performed using Analysis of Moment Structures (AMOS). Specifically, convergent construct validity (CV) for each component was assessed. Furthermore construct reliability (CR) and internal consistency reliability (Cronbach's alpha) tests were performed and the Average Variance Extracted (AVE) for each component was assessed. To address the third objective, estimates of each item's contribution and explanatory power were assessed using the beta estimate. Before the objectives were addressed, the Keiser-Meyer-Olkin $(\mathrm{KMO})$ test (a measure of sampling adequacy, $\mathrm{P}>0.60$ ) and Bartlett's Test of Sphericity (BTS, P < 0.05) (a measure of adequacy of correlation between items for factor loading) were performed. In the analysis of data, the BTS was critical for the conduct of the EFA and CFA.

\section{Results and Discussion}

Overall, three components of patient satisfaction were identified. It was proven that only the second component was valid and reliable. This is evidenced by the following results: $\mathrm{CV}=0.512 ; \mathrm{CR}=0.740$; Cronbach's alpha $=0.687$. Items 10 , 15 and 16 constituted component two, indicating that health providers expect that the cleanliness and tidiness of wards will influence patient satisfaction. Components 1 and 3 relate to provider expectations of patient satisfaction with privacy, and with adequate food servings respectively. The results of the KMO and BTS will be provided first. The results of the EFA and CFA will follow. Descriptive statistics revealed there were five male and 20 female health providers. The average number of years employed for males was 5.5 and 15.0 for females. Two of the 25 health providers were female doctors. The rest were registered nurses. Of the five males, four practiced nursing and one was a nutritionist.

Finding 1: Sampling Adequacy and Factor Correlation

Table 1 shows that the KMO index of 0.440 fell short of the lower limit of acceptance, 0.60 . It indicates that the sample size is inadequate. However, results for the BTS, $(85.16, \mathrm{df}=55, \mathrm{P}=0.006)$, indicate that there was enough correlation between items to achieve factor loadings. In addition, the P-value 0.006 suggests that the Bartlett's coefficient was quite significant $(\mathrm{P}<0.05)$. Based on 
Table 1. KMO and Bartlett's Test Results.

\begin{tabular}{cc}
\hline Kaiser-Meyer-Olkin Measure of Sampling Adequacy. & 0.440 \\
\hline Bartlett's Test of Sphericity Approx. Chi-Square & 85.164 \\
Df & 55 \\
Sig. & 0.006 \\
\hline
\end{tabular}

the Bartlett's test it was decided to continue the analysis of data via EFA and CFA.

Finding 2: Components Extracted and Variance

Table 2 illustrates that three components were extracted. In total they accounted for $57.9 \%$ of the total variance of the construct being assessed, that is patient satisfaction. Specifically, component one had the highest variance, $24.597 \%$ and component 3 the lowest, $13.434 \%$. However, component two accounted for $19.870 \%$ of the variance in patient satisfaction. The results are confirmed by the scree plot (See Figure 1) which demonstrates that eigenvalues for components 1, 2 and 3 are greater than 1 .

Results of the Rotated Component Matrix (RCM) for factor loadings are displayed in Table 3. They confirm that there are three underlying dimensions of the variable "patient satisfaction". Component one (privacy) consists of four items (2, 3, 4 and 13), component two (cleanliness and tidiness of wards) consists of three items (10, 15 and 16); and component three (food servings) consists of four items (1, 5, 6 and 11). Components are labeled after items with the highest correlation. Table 3 demonstrates that cleanliness and tidiness of wards (0.858), privacy (0.803) and food servings (0.804) were most strongly correlated to their respective component. Item correlations were generally satisfactory (> $0.70)$ for six items $(3,4,5,10,15$ and 16) across the three components. The weakest was 0.523 (item 1), satisfaction with the things health providers say to patients. It must be noted that loadings were achieved after the removal of five items $(7,8,9,12$ and 14$)$ due to cross loading.

Finding 3: Contribution and Explanatory Power of Items to Components of Patient Satisfaction

Table 4 illustrates the estimates of each item's contribution and explanatory power to "satisfaction with privacy". Item four had the highest explanatory power $(\beta=0.865)$ and item 2 the lowest $(\beta=0.450)$. The AVE was 0.420 (AVE > 0.50 is acceptable). The CR is 0.730 (CR $>0.70$ is acceptable). The Cronbach's alpha of 0.720 suggests that this dimension is a fairly reliable measure of patient satisfaction. These results suggest that CV for this dimension is not fully established. In the end, we will not accept component one because its AVE and CR are weak/low. At this time they are not shown to be useful health provider expectations of patient satisfaction.

Table 5 demonstrates the estimates of each item's contribution and explanatory power to the second dimension of the construct "patient satisfaction". Item 
Table 2. Components of Patient Satisfaction.

\begin{tabular}{|c|c|c|c|c|c|c|c|c|c|}
\hline \multirow{2}{*}{ Component } & \multicolumn{3}{|c|}{ Initial Eigenvalues } & \multicolumn{3}{|c|}{ Extraction Sums of Squared Loadings } & \multicolumn{3}{|c|}{ Rotation Sums of Squared Loadings } \\
\hline & Total & $\%$ of Variance & Cumulative \% & Total & $\%$ of Variance & Cumulative \% & Total & $\begin{array}{c}\% \text { of } \\
\text { Variance }\end{array}$ & Cumulative $\%$ \\
\hline 1 & 2.706 & 24.597 & 24.597 & 2.706 & 24.597 & 24.597 & 2.216 & 20.141 & 20.141 \\
\hline 2 & 2.186 & 19.870 & 44.467 & 2.186 & 19.870 & 44.467 & 2.191 & 19.919 & 40.060 \\
\hline 3 & 1.478 & 13.434 & 57.901 & 1.478 & 13.434 & 57.901 & 1.963 & 17.841 & 57.901 \\
\hline 4 & 1.310 & 11.913 & 69.814 & & & & & & \\
\hline 5 & 0.895 & 8.140 & 77.954 & & & & & & \\
\hline 6 & 0.859 & 7.809 & 85.763 & & & & & & \\
\hline 7 & 0.619 & 5.624 & 91.387 & & & & & & \\
\hline 8 & 0.341 & 3.096 & 94.483 & & & & & & \\
\hline 9 & 0.293 & 2.662 & 97.145 & & & & & & \\
\hline 10 & 0.193 & 1.756 & 98.902 & & & & & & \\
\hline 11 & 0.121 & 1.098 & 100.000 & & & & & & \\
\hline
\end{tabular}

Table 3. Rotated Component Matrix.

Question No.
$\begin{aligned} & \text { 4. Patients are satisfied with the level of } \\ & \text { privacy they get on wards. }\end{aligned}$
$\begin{aligned} & \text { 3. Patients are happy with the quality of their meals. } \\ & \text { 13. Patients are happy with the amount of } \\ & \quad \text { space they occupy. }\end{aligned}$ 0.720
2. Patients are satisfied with the care I give them.
15. Patients are happy to stay when the
$\quad$ ward is clean and tidy.
10. Patients are happiest when being
attended to by doctors and nurses.

Table 4. Contribution and Explanatory Power of Items Related to Satisfaction with Privacy.

\begin{tabular}{cc}
\hline Question No. & Beta Estimate \\
\hline 2 & 0.445 \\
3 & 0.565 \\
4 & 0.865 \\
13 & 0.628 \\
\hline
\end{tabular}


Table 5. Contribution and Explanatory Power of Items in Satisfaction with Cleanliness and Tidiness.

\begin{tabular}{cc}
\hline Question No & Estimate \\
\hline 10 & 0.518 \\
15 & 1.02 \\
16 & 0.478 \\
\hline
\end{tabular}

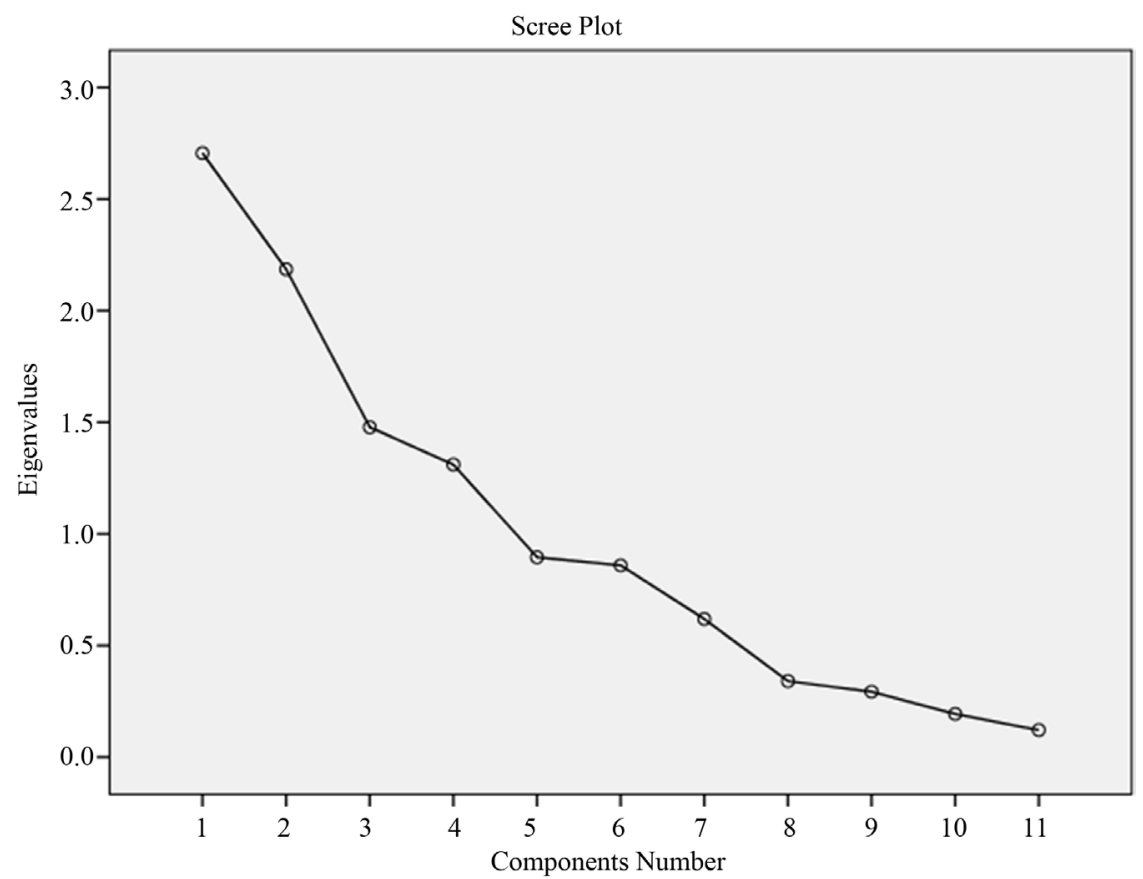

Figure 1. Scree Plot Displaying Eigenvalues for the Three Components of Patient Satisfaction.

15 had the strongest explanatory power $(\beta=1.020)$ and item 16 the weakest $(\beta=$ 0.478). The AVE was 0.512 and the CR, 0.740. These coefficients suggest that CR for this dimension was established. The Cronbach's alpha was 0.687 . This means that "satisfaction with cleanliness and tidiness" is a fairly acceptable measure of "patient satisfaction". The fact that the AVE was above 0.50 is encouraging. However, we believe that with larger samples the AVE may improve considerably.

Table 6 shows the estimates of each item's contribution and explanatory power to the third dimension of the construct "patient satisfaction". Item 11 had the highest explanatory power $(\beta=0.688)$ and item 1 the lowest $(\beta=0.445)$. The AVE was 0.310 and CR was 0.640. These values suggest that construct validity was not established. The Cronbach's alpha was 0.590 which confirms that the dimension's reliability is low. With these results we can reject component three as a useful measure of patient satisfaction.

It is obvious that component three is the least valid and reliable. Overall, items 4, 11 and 15 made the strongest contribution, whilst items 1, 2 and 16 made the 
Table 6. Contribution and Explanatory Power of Items in Satisfaction with Food Servings.

\begin{tabular}{cc}
\hline Question No. & Estimate \\
\hline 1 & 0.445 \\
5 & 0.508 \\
6 & 0.556 \\
11 & 0.688 \\
\hline
\end{tabular}

weakest contribution to their respective components. These results cannot be compared with studies cited in the literature review. In the review studies are based solely on the expectations of patients while in this paper they are based on health provider expectations.

Our findings help us to understand that the construct "patient satisfaction" is multi-factorial, that is in addition to many other factors, cleanliness and tidiness of wards in health facilities may influence patient satisfaction. In addition, this paper draws attention to the argument that expectations of health providers may be significant in measuring patient satisfaction. It helps us to understand indirect (health provider based) factors in patient satisfaction.

\section{Conclusions}

This paper presents the results of an assessment of the value of health provider expectations in measuring patient satisfaction. To achieve its aim, three objectives were specified: 1 ) to identify the number of components contained in a 16-item survey of patient satisfaction; 2) to identify items related to each component; and 3) to assess the contribution of each item to its component. The data were collected through a survey of healthcare workers attending a one day health research seminar on Saturday June 24, 2017 at the UTT. The assessment was made via the results of the EFA and CFA. The KMO and BTS were secondary assessments.

Even though the results seem discouraging, they indicate the need for further investigation of the value of health provider expectations in measuring patient satisfaction. In other words, health research should investigate the main factors that health providers' expectation will have an impact on patient satisfaction. This will improve variability in the measurement of patient satisfaction as the views of health providers will be taken into account. Lastly, this paper points to the need for a comprehensive theoretical framework of patient satisfaction so that direct and indirect measurements can be compared. Health providers play an important role in patient satisfaction. Their expectations are as significant as patients' in patient satisfaction studies.

\section{References}

[1] Aragon, S.J. and Gesell, S. (2003) A Patient Satisfaction Theory and Its Robustness across Gender in Emergency Departments: A Multigroup Structural Equation Mod- 
eling Investigation. American Journal of Medical Quality, 18, 229-241. https://doi.org/10.1177/106286060301800603

[2] Thompson, A.G.H. and Sunol, R. (1995) Expectations as Determinants of Patient Satisfaction: Concepts, Theory and Evidence. International Journal for Quality in Health Care, 7, 127-141.

https://academic.oup.com/intqhc/article-abstract/7/2/127/1795201?redirectedFrom $=\mathrm{PDF}$

[3] Linder-Pelz, S.U. (1982) Toward a Theory of Patient Satisfaction. Social Science \& Medicine, 16, 577-582. https://www.ncbi.nlm.nih.gov/pubmed/7100990

[4] Batbaatar, E., Dorjdagva, J., Luvsannyam, A. and Amenta, P. (2016) Conceptualisation of Patient Satisfaction: A Systematic Narrative Literature Review. Perspectives in Public Health, 135, 243-250.

http://journals.sagepub.com/author/Amenta\%2C+Pietro

[5] Hudak, P.L., Hogg-Johnson, S., Bombardier, C., McKeever, P.D. and Wright, J.G. (2004) Testing a New Theory of Patient Satisfaction with Treatment Outcome. Medical Care, 42, 726-739.

https://pdfs.semanticscholar.org/ced3/ee492b70fb1e80277d02dd441241865f1c88.pd f

[6] O'Connell, B., Young, J. and Twigg, D. (1999) Patient Satisfaction with Nursing Care: A Measurement Conundrum. International Journal of Nursing Practice, 5, 72-77. https://www.ncbi.nlm.nih.gov/pubmed/10633632

[7] Krajcie, R.V. and Morgan, D.W. (1970) Determining Sample Size for Research Activities. Educational and Psychological Measurement, 30, 607-610.

https://home.kku.ac.th/sompong/guest_speaker/KrejcieandMorgan_article.pdf 